\title{
Twin Circumflex Arteries: A Rare Coronary Artery Anomaly
}

\author{
Zahidullah Khan, MD; Kalyan Munde, MD; Shakil Shaikh, DM*; Narendra Bansal, MD \\ Department of Cardiology, Grant Government Medical College and Sir Jamshedjee Jeejeebhoy Group of \\ Hospitals, Mumbai, India
}

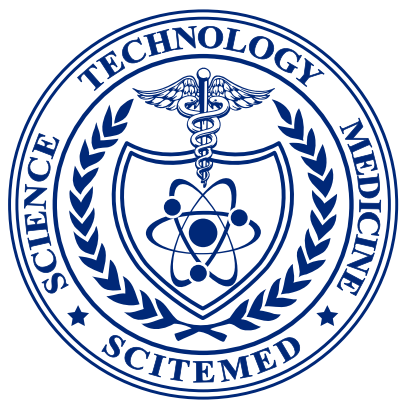

\begin{abstract}
Coronary artery anomalies are clinically important as there have been reports of sudden death and fatal and non-fatal myocardial infarction associated with exercise in persons with certain types of unusual coronary anatomy. A circumflex artery originating from an ostium apart from the left main artery is one of the most common coronary artery anomalies. However, the dual origin of the circumflex artery is an extremely rare anomaly. We describe a 45-year-old female patient admitted to our tertiary care hospital with complaints of exertional dyspnea with a positive treadmill test. Angiography revealed twin circumflex arteries: one from the left main artery and the other from the proximal right coronary artery with no significant obstructive coronary lesions; hence, advised medical management.
\end{abstract}

\section{INTRODUCTION}

Anomalies of the coronary arteries have been found in $1-2 \%$ of patients undergoing coronary angiography [1,2]. In a series of 126,595 patients studied by coronary angiography at the Cleveland Clinic, Yamanaka and Hobbs [2], the incidence was found to be $1.3 \%$ of the coronary anomalies described. One of the most common coronary anomalies is a circumflex (Cx) coronary artery anomalously originating from the right sinus of Valsalva; nevertheless, double Cx arteries originating from the left and right coronary systems constitute a type of anomaly rarely reported in the literature $[3,4]$. We present a case of twin Cx arteries: one from the left main artery and the other from the proximal right coronary artery.

\section{CASE REPORT}

A 45-year-old female, hypertensive and non-diabetic, presented with breathlessness on exertion for six months. Physical examination revealed an average built female with a pulse rate of 80 beats/min and blood pressure of 150/90 $\mathrm{mm} \mathrm{Hg}$. Peripheral pulses were normal. Cardiac auscultation revealed regular heart sounds. Routine investigations yielded no significant lipid profile abnormality. Her electrocardiogram showed a sinus rhythm with no significant ST-T changes. Echocardiography revealed no regional wall motion abnormalities with Left ventricular ejection fraction of $60 \%$. Stress (treadmill) test showed positive result for inducible ischemia by Bruce protocol's at 8 metabolic equivalents (METS). So, she was further investigated for coronary artery disease. Trans-radial coronary angiography revealed a normal left main coronary artery (LMCA) that divided into normal left anterior descending (LAD) artery and a branch that coursed toward the obtuse margin supplying the basal, mid, and distal-lateral left ventricular (LV) free wall, thereby, qualifying for the left circumflex artery (LCX) (Figure 1 and 2). The second anomalous circumflex artery and the right coronary artery (RCA) originated from a common trunk arising from the right coronary cusp (Figure 3). Hence, the patient was diagnosed with a case of twin LCX without evidence of atherosclerotic coronary artery disease. The patient was advised medical management and regular follow-up.

\section{DISCUSSION}

Normally, the left main coronary artery originates from the left sinus of Valsalva and gives rise to the LAD and Cx arteries. The $C x$ artery courses in the left atrioventricular groove and provides the first obtuse marginal branch [5]. The most frequently found anomalies include $a \mathrm{Cx}$ artery with a separate origin of the LAD and $C x$ arteries, followed by a $C x$ artery arising from the right sinus of Valsalva or the right coronary artery [6]. There are only a few cases of twin Cx arteries originating from both left and right coronary systems that have been reported in the literature. The anomalous origin of the Cx artery from the proximal right coronary artery or from the right sinus of Valsalva was first described by Antopol and Kugal in 1933 [7]. There have been many reports of anomalous coronary arteries and their association with accelerated atherosclerosis resulting in myocardial infarction and sudden death, depending upon their origin, course, and termination [8].

Some coronary artery anomalies may cause chest pain, heart failure, arrhythmia, and sudden death. These manifestations may be in consequence of the repeated compression of the anomalous artery by a dilated aortic root or of slit-like ostia or of unusual angling as a result of the retroaortic course of the Cx [9]. Myocardial ischemia can occur because of earlier and more aggressive atherosclerosis compared to a normal coronary artery found exclusively in anomalous vessels arising from the right side $[10,11]$. In a study by Wilkins, $71 \%$ of patients with an anomalous circumflex artery had significant coronary atherosclerosis in the proximal portion of the anomalous vessel [12]. An analysis from the Coronary Artery Surgery Study showed that the anomalous circumflex arteries had a significantly greater degree of stenosis than normal arteries [13]. In cases where the anomalous circumflex originates from either the right coronary artery or the right coronary sinus, its course is always retro-aortic [14]. The posterior course of the anomalous circumflex coronary artery may predispose this vessel to atherosclerosis in patients with coronary disease. Although a benign anomaly, it is important to inform the surgeons to avoid accidentally cross-clamping or transecting the artery during surgery.

\section{CONCLUSION}

Accurate recognition and documentation of coronary artery anomalies and 


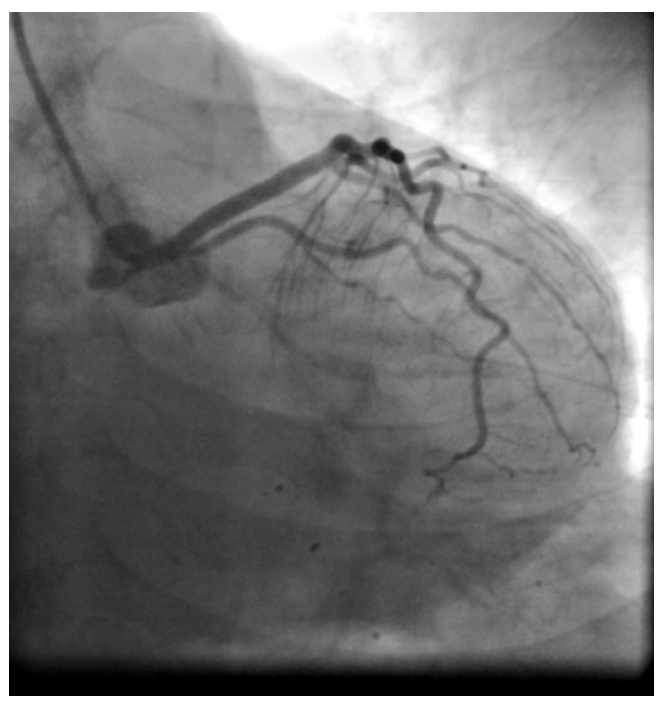

Figure 1. Left main coronary artery with left anterior descending and obtuse marginal artery in right anterior oblique caudal view.

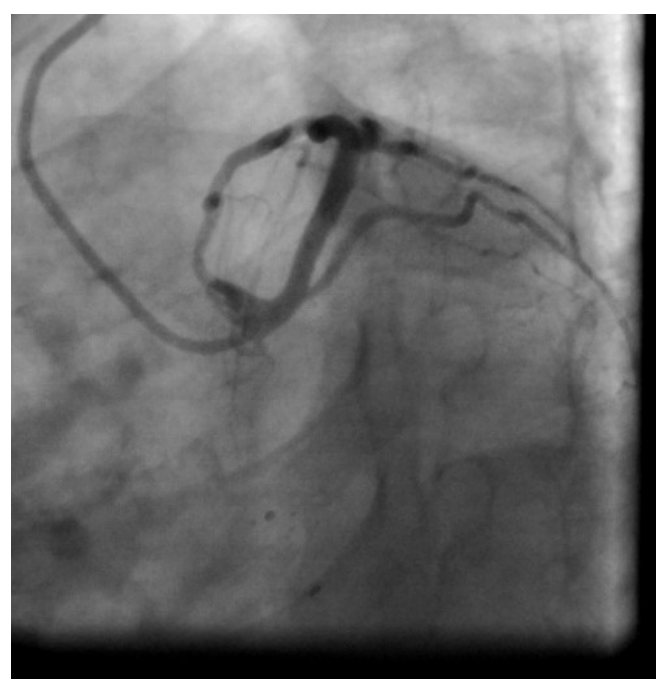

Figure 2. Left main coronary artery with left anterior descending and obtuse marginal artery in left anterior oblique caudal view.

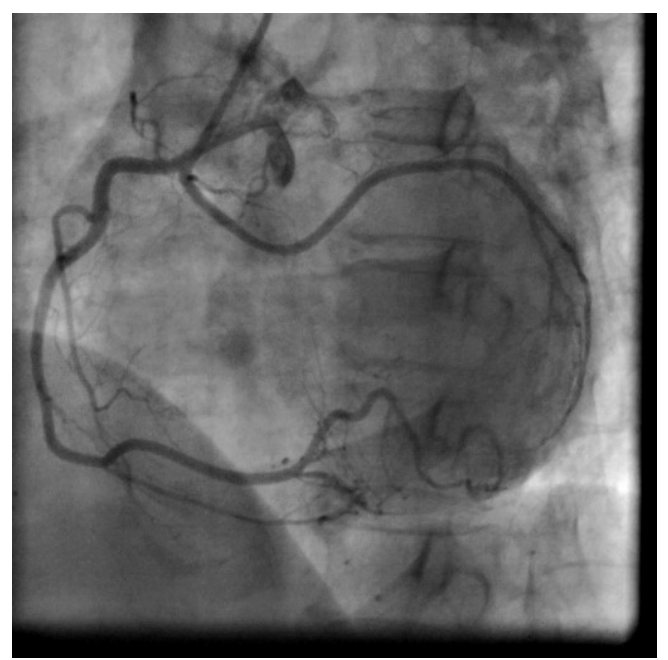

Figure 3. Anomalous left circumflex artery from right coronary artery ostium in left anterior oblique view. their course at the time of coronary angiography is essential to determine the significance of such findings and to avoid therapeutic complications. The identification of this anomaly demands a high level of anticipation during the performance of selective coronary angiography to ensure that an adequate study is obtained. Failure to recognize and properly demonstrate the anomaly may result in improper therapeutic decisions that may be hazardous to the patients. Special surgical considerations must be made when performing the valvular replacement or coronary artery bypass grafting, if desired, in such patients.

\section{ARTICLE INFORMATION}

*Correspondence: Shakil Shaikh, DM, Department of Cardiology, Grant Government Medical College and Sir Jamshedjee Jeejeebhoy Group of Hospitals, Mumbai, India. Email: drshakilsshaikh@rediffmail.com

Received: Mar. 19, 2019; Accepted: Apr. 04, 2019; Published:Jun. 26, 2019

DOI: 10.24983/scitemed.hvm.2019.00115

Ethics Approval and Consent to Participate: The study is in accordance with the ethical standards of the 1964 Helsinki declaration and its later amendments or comparable ethical standards.

Funding: The study did not receive any specific grant from funding agencies in the public, commercial, or not-for-profit sectors.

Conflict of Interest: The authors report no financial or other conflict of interest relevant to this article, which is the intellectual property of the authors.

Copyright $\odot 2019$ The Authors. This is an open-access article distributed under the terms of the Creative Commons Attribution 4.0 International License (CC-BY).

\section{REFERENCES}

1. Yamanaka O, Hobbs RE. Coronary artery anomalies in 126,595 Patients undergoing coronary arteriography. Cathet Cardiovasc Diagn 1990;21(1):28-40.

2. Kimbiris D, Iskandrian AS, Segal BL, Bemis CE. Anomalous aortic origin of coronary arteries. Circulation 1978;58(4):606-615.

3. Wilkins $\mathrm{CE}$, Betancourt B, Mathur VS, et al. Coronary artery anomalies: a review of more than 10,000 patients from the Clayton Cardiovascular Laboratories. Tex Heart Inst J 1988;15(3):166-173.

4. van der Velden LB, Bär FW, Meursing BT, Ophuis TJ. A rare combination of coronary anomalies. Neth Heart J 2008;16(11):387-389.

5. Villa AD, Sammut E, Nair A, Rajani R, Bonamini R, Chiribiri A. Coronary artery anomalies overview: the normal and the abnormal. World J Radiol 2016;8(6):537-555.

6. Angelini P, Villason S, Chan AV, Diez RJG. Normal and anomalous coronary arteries in humans. In: Coronary Artery Anomalies: A Comprehensive Approach. Angelini P, ed. Philadelphia, PA: Lippincott Williams \& Wilkins; 1999: 27-79.

7. Silverman KJ, Bulkley BH, Hutchins GM. Anomalous left circumflex coronary artery: "normal" variant of uncertain clinical and pathologic significance. Am J Cardiol 1978;41(7):1311-1314.

8. Click RL, Holmes DR Jr, Vlietstra RE, Kosinski AS, Kronmal RA. Anomalous coronary arteries: location, degree of atherosclerosis and effect on survival-a report from the Coronary Artery Surgery Study. J Am Coll Cardiol 1989;13(3):531-537.

9. Aydin M, Ozeren A, Peksoy I, et al. Myocardial Ischemia caused by a coronary anomaly: left circumflex coronary artery arising from right sinus of valsalva. Tex Heart Inst J 2004;31(3):273-275.

10. Carmelo V, Toste J, Castela S, et al. Anomalous origin of the circumflex coronary artery--two case reports. Rev Port Cardiol 2007;26(7-8):789-793.

11. Samarendra P, Kumari S, Hafeez M, Vasavada BC, Sacchi TJ. Anomalous circumflex coronary artery: benign or predisposed to selective atherosclerosis. Angiology 2001;52(8):521-526.

12. Wilkins $C E$, Betancourt $B$, Mathur VS, et al. Coronary artery anomalies: A review of more than 10,000 patients from the Clayton cardiovascular Laboratories. Tex Heart Inst J 1988;15(3):166-173.

13. Click RL, Holmes DR Jr, Vlietstra RE, Kosinski AS, Kronmal RA. Anomalous coronary arteries: location, degree of atherosclerosis and effect on survival--a report from the Coronary Artery Surgery Study. J Am Coll Cardiol 1989;13(3):531-537.

14. Turkoglu S, Ozdemir M. Anomalous origin of the left circumflex coronary artery from the right coronary artery and the left anterior descending artery from the right coronary sinus. J Invasive Cardiol 2006;18(7):E214-E216. 